\title{
Infraorbital Artery
}

National Cancer Institute

\section{Source}

National Cancer Institute. Infraorbital Artery. NCI Thesaurus. Code C52940.

An artery arising from the third portion of the maxillary artery at the trunk and running along the infraorbital canal with the superior maxillary nerve to supply the inferior rectus and inferior oblique muscles, lacrimal gland, the upper teeth, and parts of the nose and orbit. 